\title{
Mulheres encarceradas em São Paulo: saúde mental e religiosidade
}

\author{
Incarcerated women in São Paulo: mental health and religiosity
}

Paulo Augusto Costivelli de Moraes e Paulo Dalgalarrondo

\section{Resumo}

Objetivo: A religião tem um importante papel na vida de indivíduos encarcerados. A saúde mental e a possibilidade de reabilitação parecem ser favorecidas através da religião. Entretanto poucos estudos no Brasil abordaram a saúde mental em população carcerária feminina e a relacionaram com a religiosidade. 0 objetivo deste estudo é verificar o perfil de saúde mental e a relação entre religião, religiosidade e saúde mental numa amostra de mulheres encarceradas em São Paulo. Métodos: Foram entrevistadas 358 mulheres, detentas da Penitenciária Feminina da Capital (São Paulo-SP). Foi aplicado um questionário amplo que abrangeu dados sociodemográficos e culturais (incluindo a religiosidade), assim como itens sobre saúde mental e perfil criminal. A avaliação psicopatológica foi feita com o General Health Questionnaire (GHQ-12). Análises estatísticas comparando as variáveis com o GHQ-12 foram realizadas. Foi utilizada também a análise de regressão logística multivariada para respostas dicotômicas para as variáveis que possivelmente interagiram com a saúde mental. Resultados: A idade média da amostra foi 30,7 anos $\pm 8,5$. A prevalência de possível caso psiquiátrico foi $26,6 \%$. Conclusões: Uma maior religiosidade pessoal associou-se a menor freqüência de possivel transtorno mental. Não foram encontradas associações entre tipo de crime e saúde mental.

Palavras-chave: mulher, prisão, saúde mental, religião.

\begin{abstract}
Objective: Religion seems to have an important role in the life of incarcerated people. It is possible that mental health and rehabilitation are improved through religious processes. Until now, in Brazil, few studies addressed factors related to mental health in incarcerated women, especially concerning cultural variables such as religion and religiosity. The objective of this study was to verify the mental health profile and the relation between religion and the prevalence of possible mental disorders in a sample of incarcerated women from São Paulo (SP), Brazil. Methods: Three hundred fifty-eight women were interviewed in Penitenciária Feminina da Capital. A questionnaire was used which included demographic, sociocultural, religious (present and before jailing), mental health and crime profile data. For screening possible psychiatric disorders the General Health Questionnaire (GHQ-12) was used. Descriptive and bivaried statistics analysis was accomplished comparing independent variables with the GHQ-12 scores. Multivariable regression logistic analysis was used to identify variables that would possibly interact with GHQ-12 scores. Results: Mean age of the sample was $30.7 \pm 8.5$ years. The overall prevalence for possible psychiatric case was $26.6 \%$. Conclusions: A higher level of personal religiosity was associated to lower prevalence of possible mental disorders. Associations between crime type and mental health were not found.
\end{abstract}

Key words: woman, prison, mental health, religion.

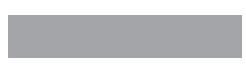

Recebido

30-11-06

Aprovado

15-03-06
Faculdade de Ciências Médicas da Universidade Estadual de Campinas (FCM/UNICAMP) (Moraes PAC, Dalgalarrondo P) 


\section{Introdução}

$\mathrm{Na}$ tradição judaico-cristã é freqüente atribuir à religião um papel determinado junto aos indivíduos que cometem crimes e foram encarcerados. A religião parece prestar-se a dar suporte emocional para homens e mulheres presos diante dos sofrimentos e privações decorrentes dessa situação específica (Oliveira, 1978; Graham, 1990). Muitos exemplos, encontrados em diferentes países e culturas, demonstram transformações importantes, decorrentes de conversão ou envolvimento religioso, nas atitudes de indivíduos que cometeram crimes. Embora esse fenômeno pareça ser bastante freqüente também no Brasil, poucos estudos sistemáticos abordaram o tema, sobretudo em mulheres.

\section{Mulheres presidiárias: a população feminina encarcerada}

Uma das possíveis conseqüências da escalada da violência em nosso país é o expressivo crescimento do número de pessoas presas. Segundo o Departamento Penitenciário Nacional (DEPEN, 2000), entre 1993 e 2000 o número de indivíduos presos cresceu cerca de $68 \%$ no estado de São Paulo e $53 \%$ no Brasil. O estado de São Paulo tinha, em 2002, cerca de 60 mil presos, 3\% deles do sexo feminino (Latin American Research Center, 2002). No Brasil as mulheres representam algo em torno de $4 \%$ da população carcerária (DEPEN, 2000), sendo tal percentual minoritário encontrado na maior parte dos países (Lemgruber, 1999; Kravitz et al., 2002; Soares e llgenfritz, 2002).

Há várias evidências que indicam uma considerável prevalência de transtornos mentais entre indivíduos encarcerados (Cardoso et al., 2004; Kravitz et al., 2004). Jordan et al. (1996) sugerem que entre um terço e a metade da população carcerária feminina britânica possa apresentar algum tipo de transtorno mental. Teplin (1996) realizou uma série de estudos sobre a prevalência de transtornos mentais graves em homens e mulheres presos na cidade de Chicago (EUA). Quando em comparação com os dados de saúde mental da população geral, a população carcerária apresentava taxas de transtornos mentais três a quatro vezes superiores às da população geral, entretanto as prevalências são ainda mais altas quando se consideram apenas as mulheres presas (excetuando-se a esquizofrenia). Os transtornos mentais mais encontrados foram depressão, abuso de substâncias psicoativas e transtorno de estresse pós-traumático. Aproximadamente $81 \%$ das mulheres presas em Chicago apresentaram ao menos um transtorno psiquiátrico ao longo da vida, de acordo com os critérios diagnósticos da terceira revisão do Diagnostic and Statistical Manual of Mental Disorders (DSM-III) (Teplin, 1996).

Existem ainda poucos estudos sobre a saúde mental da população carcerária feminina, principalmente no Brasil. Em pesquisa realizada numa penitenciária feminina em São Paulo, Almeida (1998) encontrou como sintomas mais prevalentes: insônia, ansiedade, somatização, depressão e irritabilidade. Cerca de $77 \%$ das presas entrevistadas queixaram-se de uma sensação contínua de mal-estar emocional.

\section{Religiosidade e prisão}

A religiosidade ocupa um lugar importante na vida de muitas presidiárias e altera de alguma forma a pesada rotina da unidade prisional. Diversos grupos religiosos, de diferentes tradições, fazem seus cultos e estudos doutrinários com as internas. A oferta de cultos, encontros e celebrações não decorre apenas de um direito assegurado por lei, que garante ao preso 0 atendimento religioso solicitado, mas também da crença generalizada de que a religiosidade e a espiritualidade podem trazer benefícios psíquicos e sociais para os presos e contribuírem para a tranqüilidade da unidade carcerária e a reabilitação de alguns detentos (Oliveira, 1978; Larson et al., 1997; Varella, 2000). A religiosidade, juntamente com outros fatores como trabalho, estudo, possibilidade de manutenção dos vínculos familiares, parece contribuir para um melhor ajustamento do indivíduo à realidade e para a superação de situações difíceis como a experiência do aprisionamento e da vida numa prisão de segurança máxima (Almeida, 1998).

O objetivo deste trabalho foi verificar a prevalência de possível transtorno mental e como a experiência religiosa relaciona-se com tal perfil de saúde mental numa amostra de mulheres encarceradas.

\section{Métodos}

\section{Amostra}

Os dados deste trabalho provêm de uma pesquisa original com mulheres presas que cumpriam pena na Penitenciária Feminina da Capital (PFC). Esse presídio de segurança máxima está localizado na zona norte da cidade de São Paulo (SP) e integra o Complexo Penitenciário do Carandiru. Os dados foram levantados entre março de 2003 e dezembro de 2004.

De um total inicial de 405 pessoas disponíveis, concordaram em participar e foram inclusas neste estudo 358 mulheres $(88,4 \%)$ condenadas pela prática de pelo menos um ato considerado ilegal e passível de pena de reclusão.

\section{Instrumentos}

Foi utilizado um questionário geral (QG) de autopreenchimento (com auxílio posterior à entrevistada) elaborado especificamente para este estudo. Esse instrumento teve o objetivo de obter informações sobre essa população, nos seguintes aspectos: a) levantamento de dados sociodemográficos; b) religiosidade (atual e anterior ao aprisionamento); c) saúde mental; d) perfil criminal e questões legais. Quanto aos aspectos relacionados à religiosidade, o QG investigou qual a importância atribuída naquele momento à religiosidade em sua vida (as internas, para esta questão, optaram por uma das seguintes alternativas: 1. muito religiosa; 2. religiosa; 3. pouco religiosa; 4. sem religiosidade); a existência de práticas religiosas anteriores à prisão; a filiação religiosa anterior à prisão e a freqüência com que participava dos cultos e celebrações religiosas de seu grupo religioso.

Com relação à religiosidade no período após o aprisionamento foram questionados: 1. filiação religiosa atual; 2. freqüência atual a esse culto ou igreja; 3 . filiação religiosa atual do grupo familiar (pais, irmãos, marido e filhos); 4. práticas religiosas atuais e a freqüência com que são efetuadas (prática da oração ou reza, leitura da Bíblia, e a quem recorre para obter ajuda espiritual). Perguntou-se ainda, de forma aberta, se a entrevistada havia vivenciado a experiência da conversão religiosa e, em caso afirmativo, solicitou-se uma breve descrição. 
Com relação à saúde mental, o QG recolheu as seguintes informações: 1. quem desempenhou as funções parentais; 2. ocorrência ou tentativa de fuga de casa; 3 . ocorrência de violência não-sexual durante a infância ou a adolescência; 4. ocorrência de violência sexual durante a infância ou a adolescência; 5 . comportamentos de auto-agressão (ideação suicida e tentativas de suicídio).

Também foram levantados dados sobre aspectos jurídicos e criminais: 1. data da prisão (atual); 2. artigos do Código Penal nos quais a presidiária foi enquadrada; 3 . total da pena recebida; 4. tempo já cumprido da pena; 5 . reincidência criminal; 6 . motivos existentes para o envolvimento com o crime praticado pela presidiária.

Para os aspectos referentes à saúde mental foi utilizado o General Health Questionnaire (GHQ-12), que permite rastrear possíveis transtornos mentais não-graves e detectar sintomas psicopatológicos (depressivos, ansiosos, somáticos e inespecíficos). Foi também aplicado o item de transtorno de personalidade anti-social (TPAS) do Mini-International Neuropsychiatric Interview (MINI).

\section{Procedimentos}

A aplicação de ambos os instrumentos foi feita em grupos de dez pessoas nas dependências da escola da penitenciária. Os grupos foram constituídos pelo Setor de Saúde, havendo a preocupação de incluir pessoas de diferentes pavilhões, oficinas e outros setores. Embora não tenha sido possível obter uma amostra aleatória (por condições inerentes às exigências das autoridades do presídio), esse procedimento permitiu o contato com os mais variados perfis de pessoas que formavam a população da PFC naquele momento.

Após a aplicação dos questionários e seu recolhimento, fez-se uma entrevista individual; o material escrito pelas presas era conferido (devido a respostas incompletas ou desconexas, dificuldades na leitura do material escrito), havendo a possibilidade de se levantarem novas informações e se complementarem outras.

\section{Aspectos éticos}

O protocolo deste estudo foi aprovado pelo Comitê de Ética da Faculdade de Ciências Médicas da UNICAMP.

As detentas foram informadas sobre os objetivos da pesquisa, sendo-lhes garantido o sigilo sobre as respostas e as informações dadas. Considerando a quase absoluta falta de autonomia que o sistema carcerário impõe ao indivíduo preso (Goffman, 1961; Thompson, 1976), enfatizou-se a não-obrigatoriedade da participação, sendo assegurado que a participação também não traria qualquer benefício material ou legal. Todas as participantes assinaram um termo de consentimento livre e esclarecido antes que qualquer procedimento de investigação fosse iniciado.

\section{Análise estatística}

Para a análise estatística dos dados coletados foram feitas análises descritivas das variáveis categóricas. Na comparação dos escores obtidos no GHQ-12 com relação às variáveis categóricas foi utilizado o teste qui-quadrado. Para verificação das variáveis que influenciaram nos escores do GHQ-12 (possível caso x possível não-caso) foi utilizada a análise de regressão logística multivariada para respostas dicotômicas.

\section{Resultados}

$\mathrm{Na}$ amostra de 358 presidiárias, a idade média foi 30,7 anos $\pm 8,5$ e a mediana, 29 anos. Essa população é composta em grande parte por mulheres brancas $(48,5 \%)$, solteiras $(52 \%)$ e mães de 2,1 $\pm 1,7$ filhos com mediana de dois filhos. Quanto ao número de anos de estudo com sucesso, foi encontrado o tempo médio de 5,9 anos $\pm 2,9$ e a mediana de cinco anos. Nasceram no estado de São Paulo 68,5\% da amostra. A Tabela 1 apresenta dados sociodemográficos mais específicos da amostra como estado

Tabela 1. Estado civil, número de filhos, escolaridade e profissão

\begin{tabular}{|c|c|c|}
\hline & $n$ & $\%$ \\
\hline \multicolumn{3}{|l|}{ Estado civil } \\
\hline Casadas/amasiadas & 108 & 30,2 \\
\hline Separadas & 34 & 9,5 \\
\hline Solteiras & 186 & 52 \\
\hline Viúvas & 30 & 8,4 \\
\hline Total & 358 & 100 \\
\hline \multicolumn{3}{|l|}{ Número de filhos } \\
\hline Sem filhos & 45 & 21,2 \\
\hline 1 ou 2 & 94 & 44,3 \\
\hline 3 a 5 & 63 & 29,7 \\
\hline 6 ou mais & 10 & 4,7 \\
\hline Total & 212 & 100 \\
\hline \multicolumn{3}{|c|}{ Escolaridade (anos de estudo com sucesso) } \\
\hline$\leq 1$ & 13 & 3,6 \\
\hline 2 a 4 & 145 & 44,1 \\
\hline 5 a 7 & 88 & 24,6 \\
\hline 8 a 10 & 89 & 24,9 \\
\hline 11 anos ou mais & 23 & 6,4 \\
\hline Total & 358 & 100 \\
\hline \multicolumn{3}{|l|}{ Profissões } \\
\hline $\begin{array}{l}\text { 1. Comerciantes, balconistas, } \\
\text { vendedoras sem especialização }\end{array}$ & 76 & 21,3 \\
\hline $\begin{array}{l}\text { 2. Auxiliares de limpeza, domésticas, } \\
\text { faxineiras, lavadeiras, arrumadeiras, } \\
\text { copeiras }\end{array}$ & 75 & 21,1 \\
\hline 3. Donas-de-casa & 38 & 10,7 \\
\hline $\begin{array}{l}\text { 4. Atendentes, recepcionistas, } \\
\text { ajudantes gerais, telefonistas }\end{array}$ & 27 & 7,6 \\
\hline 5. Costureiras (autônomas) & 15 & 4,2 \\
\hline $\begin{array}{l}\text { 6. Secretárias, assistentes } \\
\text { administrativas, auxiliares de escritório }\end{array}$ & 15 & 4,2 \\
\hline 7. Outros & 110 & 30,9 \\
\hline Total & 356 & 100 \\
\hline
\end{tabular}


civil, número de filhos, anos de estudo com sucesso e profissões exercidas antes do aprisionamento.

$\mathrm{Na}$ Tabela 2 são apresentados os tipos de crime praticados, especificando-se o que foi considerado violento, nãoviolento, relacionado ao tráfico de drogas e combinados. Nessa tabela apresentam-se também a pena imposta (em anos) e 0 tempo durante o qual a mulher está presa.

Tabela 2. Tipos de crime praticados, pena estipulada, tempo cumprido

\begin{tabular}{|c|c|c|}
\hline Tipos de crime praticados & $n$ & $\%$ \\
\hline \multicolumn{3}{|l|}{ Crime violento } \\
\hline 1. Homicídio (art.121) & 38 & 10,6 \\
\hline 2. Lesão corporal (art.129) & 2 & 0,6 \\
\hline 3. Roubo (art.157) & 103 & 28,8 \\
\hline 4. Latrocínio (art.157.3) & 19 & 5,3 \\
\hline 5. Seqüestro (art.159) & 21 & 5,9 \\
\hline 6. Extorsão (art.158) & 1 & 0,3 \\
\hline Total & 184 & 51,5 \\
\hline \multicolumn{3}{|l|}{ Tráfico de drogas } \\
\hline $\begin{array}{l}\text { 1. Comércio, porte, consumo, } \\
\text { etc. (art.12 e outros) }\end{array}$ & 151 & 42,2 \\
\hline Total & 151 & 42,2 \\
\hline \multicolumn{3}{|l|}{ Crimes não-violentos } \\
\hline 1. Furto (art.155) & 13 & 3,6 \\
\hline 2. Estelionato & 3 & 0,8 \\
\hline Total & 16 & 4,4 \\
\hline Crimes combinados & 7 & 1,9 \\
\hline 1. Total de crimes violentos & 184 & 51,5 \\
\hline 2. Total de tráfico de drogas & 151 & 42,2 \\
\hline 3. Total de crimes não-violentos & 16 & 4,4 \\
\hline 4. Total de crimes combinados & 7 & 1,9 \\
\hline Total geral & 358 & 100 \\
\hline \multicolumn{3}{|c|}{ Tempo total da pena (anos) } \\
\hline 1 a 3 & 5 & 1,5 \\
\hline 3,1 a 6 & 148 & 45,8 \\
\hline 6,1 a 10 & 78 & 24,1 \\
\hline Mais de 10 & 92 & 28,6 \\
\hline Total & 323 & 99,9 \\
\hline \multicolumn{3}{|l|}{ Tempo de pena cumprido (anos) } \\
\hline Até 1 & 64 & 18,3 \\
\hline 1,1 a 5 & 238 & 68,2 \\
\hline 5,1 e mais & 47 & 13,5 \\
\hline Total & 349 & 100 \\
\hline
\end{tabular}

Em relação à religiosidade, identificou-se que antes do aprisionamento $257(72 \%)$ presas tinham práticas religiosas, 151 (42\%) eram evangélicas, 94 (26\%) eram católicas e 95 (26\%) não tinham religião. Um terço delas tinha freqüência assídua a cultos, um terço a tinha irregular e outro terço não freqüentava reuniões religiosas. Cinqüenta e sete por cento das presas referiram ter tido uma experiência de conversão religiosa em suas vidas. Quanto à intensidade da religiosidade no momento, $86 \%$ declararam-se muito religiosas ou religiosas.

A Tabela 3 mostra os dados de afiliação religiosa das presas no momento atual (após o aprisionamento) e a comparação entre a afiliação religiosa das presas e a de suas famílias, permitindo que se percebam as relações entre histórico familiar e transformações vivenciadas pelas internas depois que foram encarceradas.

Tabela 3. Igrejas e cultos das presidiárias e de suas famílias

\begin{tabular}{lcccc}
\hline \multirow{2}{*}{ Igrejas e cultos } & \multicolumn{2}{c}{ Presas } & \multicolumn{2}{c}{ Famílias } \\
\cline { 2 - 5 } & $n$ & $\%$ & $n$ & $\%$ \\
\hline Igreja Católica & 56 & 15,6 & 119 & 33,2 \\
Romana & & 56,2 & 176 & 49,2 \\
Igrejas evangélicas & 201 & 5 & 5 & 1,4 \\
Espiritualistas & 18 & 5 & 58 & 16,2 \\
Não freqüenta ou & 83 & 23,2 & 58 & 100 \\
sem resposta & & & & \\
Total & 358 & 100 & 358 & \\
\hline
\end{tabular}

A Tabela 4 traz informações sobre a saúde mental das internas, mostrando os resultados obtidos com o GHQ-12 e informações sobre a prevalência do TPAS.

$\mathrm{Na}$ Tabela 5 é apresentada a relação entre a intensidade de envolvimento religioso (como a pessoa se considera em relação à vida religiosa) e o escore obtido no GHQ-12, que indica se o sujeito é um possível caso de transtorno mental.

Tabela 4. Resultados do GHQ-12 e da prevalência de transtorno de personalidade anti-social pelo MINI

\begin{tabular}{lcc}
\hline GHQ-12* $^{*}$ & $\boldsymbol{n}$ & $\%$ \\
\hline Resultados - Caso x não-caso & & \\
\hline 1. Caso $(\leq 4)$ & 95 & 26,6 \\
2. Não-caso ( $\geq 4)$ & 262 & 73,4 \\
Total & 357 & 100 \\
\hline \multicolumn{2}{l}{ Prevalência de transtorno de personalidade anti-social } \\
(MINI) \\
\hline 1. Caso & 55 & \\
2. Não-caso & 297 & 84,4 \\
Total & 352 & 100 \\
\hline
\end{tabular}

${ }^{*}$ Missing: $1 ;{ }^{* *}$ missing: 6. 


\begin{tabular}{|c|c|c|c|c|}
\hline GHQ-12 & $\begin{array}{l}\text { Muito } \\
\text { religiosa }\end{array}$ & Religiosa & $\begin{array}{l}\text { Pouco } \\
\text { religiosa/ } \\
\text { sem } \\
\text { religião }\end{array}$ & Total \\
\hline Caso $(\geq 4)$ & $27(28,7)$ & $45(47,9)$ & $22(23,4)$ & $94(26,4)$ \\
\hline Não-caso (<4) & $85(32,4)$ & $149(56,9)$ & $28(10,7)$ & $262(73,6)$ \\
\hline Total & $112(31,5)$ & $194(54,5)$ & $50(14)$ & $356(100)$ \\
\hline
\end{tabular}

Teste qui-quadrado: $p=0,0096$.

Finalmente, realizaram-se análises de regressão logística bivariada e multivariada que investigaram todas as variáveis colhidas e a sua influência sobre os escores do GHQ-12. Nas análises de regressão logística bivariada, as únicas variáveis que se associaram significativamente a um escore acima de 3 no GHQ-12 (possível caso) foram: ter perdido o sono ultimamente (odds 4,12; IC: 2,39-7,8; $p<0,001$ ), ter menor intensidade do envolvimento religioso (odds 2,47 ; IC: 1,22-5,01; $p<0,05$ ), ter tido idéias suicidas no passado (odds 1,85; IC: 1,15-2,98; $p<0,05$ ) e ter tido uma tentativa de suicídio no passado (odds 1,86; IC: 1,1-3,14; $p<0,05)$. Também revelaram tendência à significação estatística as variáveis ter sofrido agressão sexual na infância (odds 1,67; IC: $0,97-2,9 ; p=0,06$ ) e família não freqüentar a igreja (odds 1,79; IC: $0,96-3,34 ; p=0,07)$.

Na regressão logística multivariada apenas se mantiveram no modelo final ter perdido o sono ultimamente (odds 4,44; IC: 2,54$7,76 ; p<0,001)$ e ter tido uma tentativa de suicídio no passado (odds 2,12; IC: 1,21-3,71; $p<0,001$ ).

\section{Discussão}

Os dados apresentados neste trabalho concordam com a evidência, demonstrada pelas literaturas nacional e internacional, da importância da religiosidade na vida de sujeitos encarcerados; no presente trabalho $86 \%$ das presas afirmaram ser muito religiosas ou religiosas.

Parece ser consenso entre os autores que estudam a situação carcerária brasileira que a maior parte dessa população é formada por indivíduos oriundos principalmente dos segmentos sociais marcados pela exclusão social, política e econômica (Palma et al., 1996; Lemgruber, 1999). A presente pesquisa encontrou que grande parte das internas nessa penitenciária procede das camadas menos favorecidas da sociedade, o que pode ser constatado pela baixa escolaridade, pelo predomínio de ocupações de baixa qualificação e salários proporcionais, por históricos de vida marcados pela precariedade material, educacional e afetiva e por acontecimentos traumáticos como perda precoce do amparo parental, violência física e sexual, evasão do lar, entre outros.

Quanto à afiliação religiosa, cerca de $56 \%$ das internas declarou participar das igrejas evangélicas, especialmente das neopentecostais que atuam na PFC, como a Igreja Apostólica Renascer em Cristo (Renascer) e a Igreja Universal do Reino de Deus (IURD). Esse dado difere bastante do encontrado para a população geral. De acordo com o Censo 2000 (Jacob et al., 2003), $15,6 \%$ da população brasileira total declarou-se filiada a igrejas evangélicas.

Pesquisas anteriores haviam revelado que, na população carcerária brasileira, os percentuais de afiliação a igrejas evangélicas variava entre $25 \%$ e $30 \%$ (Oliveira, 1978; Lemgruber, 1999; Latin American Center Research, 2002). Assim, os dados de 42\% (antes da prisão) e de $56 \%$ (no momento da pesquisa) de afiliadas a igrejas evangélicas encontrados no presente trabalho são, de certa forma, surpreendentemente altos.

Essa diferença talvez possa ser explicada por alguns fatos como dupla afiliação religiosa (igrejas evangélicas e igreja católica, igrejas evangélicas e grupos kardecistas, etc.) ou pela vigorosa, crescente e permanente atuação das igrejas neopentecostais tanto fora (nos segmentos mais pobres e excluídos da sociedade brasileira) quanto dentro da penitenciária, em especial a IURD, a Renascer (igreja evangélica mencionada mais vezes durante 0 período em que a pesquisa foi feita) e a Comunidade da Graça. Em particular, dentro da penitenciária feminina de São Paulo, a Renascer tem uma intensa ação social e proselitista.

Para Pierucci e Prandi (1996) as religiões de conversão, notadamente as neopentecostais, crescem na pobreza e na marginalidade social. Anteriormente O'Dea (1969) e D'Epinay (1970) apontaram o crescimento da religiosidade pentecostal entre as classes mais pobres. Entendiam, a partir de uma perspectiva sociológica, que a adesão às igrejas evangélicas - especialmente as pentecostais - era uma maneira de indivíduos que tinham sido obrigados a abandonar um tipo de sociedade mais tradicional (rural ou agrária) e se deslocar para outras áreas (urbanas ou mais modernas) se organizarem e se adaptarem a uma nova realidade. Berger (1995) também entende a religião como uma defesa importante contra a anomia social e também como poderosa força de reprodução social. Para Rolim (1981) a vinculação do pentecostalismo (clássico) às camadas populares desprivilegiadas faz parte da história e da própria identidade dessa corrente protestante.

Um dado original e mesmo surpreendente deste trabalho foi a constatação de que o envolvimento com as igrejas evangélicas muitas vezes é anterior ao aprisionamento, encontrando-se um número significativo de famílias de mulheres presas que se declaram evangélicas: $49,2 \%$ das famílias das entrevistadas são evangélicas pentecostais, havendo a possibilidade de que diversas presidiárias tenham sido criadas freqüentando algumas dessas igrejas. Assim, a hipótese difundida pelo senso comum de que nos bolsões de miséria da sociedade brasileira a afiliação a igrejas evangélicas protegeria contra o envolvimento criminal parece ser questionada pelos dados do presente trabalho. É possível que nos meios populares de grande adversidade socioeconômica e cultural ocorram, de fato, negociações simbólicas muito mais complexas do que 0 aparente moralismo rígido da religiosidade evangélica faz supor e o senso comum registra: negociações que integrem a necessidade de religiosidade, valores flexíveis e mutantes relacionados a normas e transgressão, assim como formas de constituir a subjetividade e a identidade e se adaptar às contingências da vida.

Aproximadamente $57 \%$ das internas afirmaram ter vivido a experiência da conversão religiosa. Entretanto existem várias e diferentes interpretações quanto a natureza, significado e conseqüências do fenômeno, tanto entre os sociólogos quanto entre teólogos e religiosos. Para James (1995) a conversão 
religiosa é uma experiência profunda, intensa e arrebatadora que possibilita a integração da personalidade, trazendo sentimentos de segurança e bem-estar ao indivíduo. Segundo Alves (1982), o sujeito que se converte passará a dividir sua vida em duas metades: antes e depois da conversão. A consciência de pecado e imperfeição é substituída por sentimentos de renovação, de novidade de vida, um novo nascimento, segundo a linguagem bíblica.

A título de exemplo, reproduzimos aqui duas falas pertinentes que exemplificam as teses desses autores:

"Sonho com o dia que eu reencontre o meu Salvador. Sou ingrata com o meu Deus, meu coração pende aos desejos carnais, então às vezes fico com vergonha de Deus porque eu não O mereço. Eu me preparei durante meses buscando a conversão verdadeira, porém depois do batismo eu me rebelei completamente" (GEMF, 31 anos, presa por tráfico de drogas - Igreja Universal).

"Foi bom [a conversão religiosa], mas como não somos justos e eu sei que sou muito falha, acabei caindo. Não tenho muito mais o que falar. Caí!" (CEM, 28 anos, presa por tráfico de drogas - Igreja Universal).

\section{Possível transtorno mental entre as presas}

A aplicação do GHQ-12 identificou 95 pessoas com pontuação igual ou acima de 4 , representando $26,6 \%$ da amostra. Esse resultado foi próximo (ou um pouco abaixo) dos mencionados por Almeida Filho (1997) e Costa (2001) para a população brasileira em geral e substancialmente inferior aos encontrados para as mulheres presas na Irlanda, em 1999 (WHO, 2000; Kravitz et al., 2002). Nesse país, em 13 prisões foi utilizado o GHQ-12 (nota de corte 3) numa amostra de 800 pessoas de ambos os sexos. Nas prisões irlandesas estudadas, a aplicação do GHQ-12 demonstrou que $48 \%$ da população masculina e $75 \%$ da feminina foram considerados possíveis casos psiquiátricos. Essas pessoas passaram por entrevistas psiquiátricas posteriores, tendo sido constatado um nível muito elevado de ansiedade e depressão entre os entrevistados, conforme indicado pelo questionário Health in Prisons Project.

Como mencionado anteriormente, Teplin et al. (1996) encontraram que aproximadamente $80 \%$ da população estudada teria desenvolvido ao menos um sintoma psicopatológico significativo ao longo da vida.

O item de transtorno de personalidade anti-social do MINI evidenciou uma freqüência de 15,6\%. A freqüência por nós encontrada foi muito inferior às relatadas por outros autores (Rigonatti, 2003).

Os resultados do presente estudo revelando baixa prevalência de possíveis casos psiquiátricos devem ser analisados com cautela. Deve-se considerar que portadores de transtornos psiquiátricos mais graves não permanecem nas penitenciárias, sendo transferidos para os hospitais judiciários. Isso é feito por força de lei e também porque pacientes psiquiátricos podem causar problemas sérios em um ambiente comumente tenso e agitado. Mas tal procedimento não é exclusividade do sistema carcerário brasileiro e possivelmente também tem sua influência (reduzindo as prevalências) nos estudos mencionados.

Também é necessário considerar a possível influência de uma certa cultura institucional ou ethos da prisão. De acordo com depoimento de psicólogas da penitenciária e também notado cla- ramente por um dos pesquisadores (PACM), em um meio violento como o existente na PFC não há espaço ou condições para que as pessoas demonstrem fragilidade ou se exponham excessivamente. O ethos penitenciário parece exigir que as pessoas sejam ou muito fortes e dominadoras ou extremamente sagazes. E esse ethos poderia ter interferido nas respostas dadas pelas presidiárias.

No modelo de regressão logística multivariado apenas as variáveis ter perdido o sono ultimamente e ter tido uma tentativa de suicídio no passado permaneceram significativas no modelo final. Esse resultado implica apenas que o sofrimento atual das mulheres que obtiveram pontuação mais alta no GHQ-12 se relaciona com as dificuldades presentes ao longo de suas vidas (tentativas de suicídio no passado). Sendo o sono um dos itens do próprio $\mathrm{GHQ}$ 12, 0 achado é, de fato, redundante.

Comparando o grau de envolvimento das presidiárias com a religiosidade e a saúde mental, foi encontrada nas análises bivariadas uma associação positiva para esses itens. Na população pesquisada, as mulheres que se declararam muito religiosas e religiosas apresentaram menos freqüências de caso do que as pessoas que se declararam pouco religiosas ou sem religião.

Embora esse achado não se tenha mantido no modelo multivariado, pode-se sugerir esteja na mesma linha de achados da literatura internacional (Larson et al., 1997; Koenig e Larson, 2001; Dalgalarrondo, 2004) que indicam ser a religiosidade, de forma geral, um elemento protetor da saúde mental. É possível que a religiosidade contribua para a recuperação da auto-imagem do indivíduo preso. No caso específico da PFC, é possível que a adesão a uma nova forma de religiosidade contribua para a sensação de ter sido perdoado de seus pecados, deixando de se considerar apenas um criminoso para se transformar em filho de Deus. Ocorreria um processo culturalmente sancionado de reconstituição da identidade e de criação de novas perspectivas para a trajetória de vida, pelo menos para algumas das mulheres estudadas.

A religiosidade também pode representar um sentido para a áspera experiência do aprisionamento, o que ajudaria a presa a enfrentar o cotidiano de uma penitenciária. A transcrição a seguir da fala de uma presa objetiva exemplificar como a religiosidade atuou em sua vida. Ela é solteira, analfabeta e mãe de três filhos que no momento da entrevista, moravam em uma favela de São Paulo sob os cuidados de uma amiga. Cumpre observar que a situação dos filhos era motivo de grande preocupação para a entrevistada. Perguntada sobre como a religiosidade interferia no seu cotidiano, respondeu da seguinte forma:

"Eu quero ser serva de Jesus. Entrego tudo nas mãos de Deus. Eu não sou neurótica, nunca briguei aqui. (...) Deus alegra a gente. Mas o lugar é triste, muito triste, entristece a gente. Peço para tirar uma palavra na Bíblia. E Deus fala claramente, a gente pede e Ele fala e acalma... Ele coloca a gente num lugar como este pra gente ver que Ele existe. Isto [a penitenciária] é coisa do inimigo [Satanás]... Estou mais calma agora, se Jesus fala [promete], eu vou sair desta vida". (43 anos, presa por tráfico de drogas - Igreja Universal).

\section{Conclusão}

O presente trabalho encontrou uma prevalência relativamente baixa de transtornos mentais em mulheres encarce- 
radas no Presídio Feminino de São Paulo. Verificou também possíveis relações positivas entre religiosidade e saúde mental junto a mulheres presas, concordando em parte com a literatura existente. Observou alta freqüência de presas afiliadas a igrejas evangélicas, embora estas circulem entre as diferentes confissões e cultos existentes na unidade prisional.

É plausível que a conversão religiosa contribua para a reconstrução da auto-imagem e forneça um sentido para a existência do indivíduo, não só para a sua situação de encarcerado, mas também para outros aspectos como pobreza e exclusão social, falta de trabalho, desestruturação familiar, entre outros.

Ao contrário do imaginado pelo senso comum, não foram encontrados dados sugestivos de que a religiosidade pudesse evitar 0 envolvimento com a criminalidade. Assim a suposição de que nos bolsões de pobreza das grandes cidades brasileiras a presença maciça de igrejas pentecostais e neopentecostais inibe comportamentos criminosos não foi evidenciada empiricamente por este trabalho (pois mais de $40 \%$ das presas já eram evangélicas antes do aprisionamento). Foi encontrado um expressivo interesse religioso anterior ao aprisionamento, questão que mereceria estudos posteriores envolvendo a população geral e estudos etnográficos nas comunidades.

A questão da saúde mental da população carcerária é relativamente pouco estudada no Brasil. O tema é de grande importância por estar relacionado com o crescimento da violência em todo o país, pela importância da religiosidade, sobretudo nas classes populares, e por serem as presidiárias um dos grupos minoritários substancialmente negligenciados por estudos científicos e por ações de reabilitação.

\section{Referências}

Almeida Filho N, Mari JJ, Coutinho E, França JF, Fernandes F, Andreoli $\mathrm{SB}$, Busnello EA. Brazilian multicentric study of psychiatric morbidity. Br J Psychiatry, 171: 524-9, 1997.

Almeida KM. Metáforas de um pena capital: um estudo sobre a experiência prisional e suas relações com a saúde mental das presidiárias. Tese de mestrado apresentada ao Instituto de Saúde Coletiva da Universidade Federal da Bahia, 1998.

Alves R. Protestantismo e repressão. São Paulo: Ática; 1982.

Berger P. O dossel sagrado: elementos para uma teoria sociológica da religião. São Paulo: Paulinas; 1985.

Bonfatti P. A expressão popular do sagrado: uma análise psicoantropológica da Igreja Universal do Reino de Deus. São Paulo: Paulinas, 2000.

Cardoso RG, Blank P, Taborda JGV. Exame de superveniência de doença mental. In: Taborda JGV, Chalub M, Abdalla Filho E. Psiquiatria Forense. Artmed, p. 151-60, Porto Alegre, 2004.

Costa EC. Concordância entre as escalas de rastreamento GHQ-12 (General Health Questionnaire) e GHQ-30 em corte de idosos de base populacional. Tese de mestrado apresentada na FMUFMG, 2001.

Dalgalarrondo P, Soldera MA, Corrêa Filho HR, Silva CAM. Religião e uso de drogas por adolescentes. Rev Bras Psiquiatr, 26(2): 82-90, 2004.

DEPEN. Censo Carcerário do Brasil. Fundação SEADE/DEPEN, Brasília, 2000.

D'Epinay L. O refúgio das massas. Rio de Janeiro: Paz e Terra; 1970.

D'Orban PT, Maden A, Taylor P. Female offenders. In: Gunn J, Taylor P. Forense Psychiatry: clinical, legal and ethical issues. Butterworth Heinemann, p. 599-623, Oxford, 1993.

Graham WR. Prisoners and prison chaplaincy. In: Dictionary of pastoral care and prision counseling. Hunter RJ, general editor. Abingdon Press, Nashville, 1990.

Goffman E. Manicômios, prisões e conventos. São Paulo: Perspectiva; 2003.

Jacob CR, Hees DR, Waniez P, Brustlein V. Atlas da filiação religiosa e indicadores sociais no Brasil. Edições Loyola: São Paulo; 2003.

James W. As variedades da experiência religiosa: um estudo sobre a natureza humana. São Paulo: Cultrix; 1995.
Jordan K, Schlenger WE, FairbankA, Caddell JA. Prevalence of psychiatric disorders among incarcerated women. Arch Gen Psychiatry, 53: 513-9, 1996.

Koenig HG, Larson DB. Religion and mental health: evidence for an association. Intern Rev Psychiatry, 13: 67-78, 2001.

Kravitz HM, Cavanaugh Jr JL, Rigsbee SS. A cross-sectional study of psychosocial and criminal factors associated with arrest in mentally ill female detainees. J Am Acad Psychiatry Law, 30: 380-90, 2002

Latin American Center Research. O perfil do preso no Estado de São Paulo: Caderno de Anexos. Novembro, 2002.

Larson D, Swyers JP, McCullough ME. Scientific research on spirituality and health: a consensus report. National Institute for Healthcare Research. Sponsored by The John Templeton Foundation, 1997.

Lemgruber, J. Cemitério dos vivos: sociologia de uma prisão de mulheres. Rio de Janeiro: Forense; 1999.

O'Dea T. Sociologia da religião. São Paulo: Pioneira; 1969.

Oliveira MMC. A religião nos presídios. São Paulo: Cortez e Moraes. Série estudos penitenciários; volume 2, 1978.

Palma AC, Rogerio I, Neves LCD. A questão penitenciária e a letra morta da lei. Curitiba: JM Editora; 1997.

Pierucci AF, Prandi R. A realidade social das religiões no Brasil: religião, sociedade e política. São Paulo: Hucitec; 1996.

Rigonatti SP. Temas em psiquiatria forense e psicologia jurídica. São Paulo: Vetor, 2003

Rolim FC. Gênese do pentecostalismo no Brasil. Rev Eclesiástica Brasileira, 161: 119-40, 1981.

Soares BM, llgenfritz I. Prisioneiras: vida e violência atrás das grades. Rio de Janeiro: Garamond; 2002.

Teplin LA, Abram KM, McClelland GM. Prevalence of psychiatric disorders among incarcerated women: I. pretrial jail detainees. Arch Gen Psychiatry, 53: 505-12, 1996.

Thompson A. A questão penitenciária. Rio de Janeiro: Forense; 2002.

Varella D. Estação Carandiru. São Paulo: Companhia das Letras; 1999. WHO (World Health Organization). Health in Prisons Project, 2000. 